\title{
Preparation of Poly(Urethane-urea) Nanoparticles Containing Açaí Oil by Miniemulsion Polymerization
}

\author{
Alexsandra Valério, Pedro H. H. Araújo, Claudia Sayer \\ Department of Chemical and Food Engineering, Federal University of Santa Catarina, UFSC
}

Abstract: Polyurethane nanoparticles (NPs) are promising candidates for the controlled and targeted delivery of therapeutics in a variety of biomedical applications. In this work, a report is made of NPs produced by miniemulsion polymerization with isophorone diisocyanate (IPDI) and castor oil, glycerol, and poly(ethylene glycol) (PEG) with molar masses 400 and 1000 as monomers and Tween 80, Span 80 and Lutensol AT 25 as surfactant and açaí oil as costabilizer. Stable dispersions with sizes between 100 - $500 \mathrm{~nm}$ were achieved. The effects from polyol, types and concentration of surfactant and reaction temperature on the size of the NPs and weight average molar mass were evaluated. Morphological characterization was accomplished using images from Transmission Electron Microscopy (TEM) and Scanning Electron Microscope (SEM).

Keywords: Miniemulsion polymerization, poly(urea-urethane), açaí oil.

\section{Introduction}

In recent years polymeric nanoparticles (NPs) have gained increasing popularity as promising vehicles for delivering drugs, and others agents ${ }^{[1,2]}$. In addition, the development of biocompatible poly(urethaneurea) (PUU) has drawn much attention due to their excellent physical properties, biocompatibility and biodegradability and the potential value has been discussed for a variety of pharmaceutical, medical, and cosmetic applications such as medium for controlled release $\mathrm{e}^{[1-6]}$.

PUU particles have been synthesized using several techniques such as suspension, miniemulsion and interfacial polymerization ${ }^{[7-9]}$. Miniemulsion is defined as dispersions of relatively stable oil droplets with a size range 50-500 $\mathrm{nm}$, prepared by shearing a system containing oil, water, surfactant and costabilizer ${ }^{[10-12]}$. In principle, polymerization occurs in submicrometric droplets allowing the encapsulation of different compounds via step polymerizations. As reported by Tiarks and Landfester, when PUU particles are prepared by direct oil in water miniemulsion polymerization two reaction paths may occur: 1) polyaddition of isocyanate with the polyol to form urethane and 2) hydrolysis of isocyanate to form urea with $\mathrm{CO}_{2}$ release ${ }^{[13]}$. This second reaction path results in a loss of stoichiometry, as well as to the formation of polymers with a lower molar mass ${ }^{[14,15]}$, and thus, is usually sought to be minimized. In this sense the use of a slowly reacting diisocyanate, as isophorone diisocyanate (IPDI), is advised for the synthesis of PUU via direct miniemulsion polymerization in order to reduce the reaction with water which composes the continuous phase $\mathrm{e}^{[5,13,16]}$.

Several vegetable oils that are mainly composed of triacylglycerols have attracted the attention of pharmaceutical and cosmetic industries due to their properties. Açaí (Euterpe oleracea) pulp oil is rich in oleic and linoleic acids, showing properties as epidermis regeneration, stimulus for cicatrization and moistening ${ }^{[17,18]}$.
In this work we describe the synthesis of PUU NPs by step miniemulsion polymerization with the incorporation of high amounts of açaí oil. The influence of reaction conditions as type of polyol, reaction temperature, surfactant type and concentration, on the PUU NPs was verified.

\section{Experimental}

\section{Chemicals}

Isophorone diisocyanate (IPDI, 98\%, Mw $222 \mathrm{~g} / \mathrm{mol}$ ) was provided by Killing S.A. Castor oil $(100 \%$, Mw $928 \mathrm{~g} / \mathrm{mol}$ ), a triacylglycerol in which most of the fatty acid chains are composed of ricinoleic acid ${ }^{[19]}$, a monounsaturated fatty acid that contains a hydroxyl group, was purchased from Linfar and poly(ethylene glycol) with average molar mass of either 950 to $1050 \mathrm{~g} / \mathrm{mol}$ (PEG 1000) or 380 to $420 \mathrm{~g} / \mathrm{mol}$ (PEG 400) was purchased from Sigma Aldrich. Açaí oil, a triacylglycerol of predominantly monounsaturated fatty acids (oleic acid), used as costabilizer, was provided by Beraca and surfactants Tween 80, Span 80 and Lutensol AT 25 were, respectively from Oxiteno, Sigma Aldrich and BASF. The tetrahydrofuran (THF) was used as solvent in the molar mass analyses. The chemicals were used as received.

\section{Miniemulsion polymerization}

The PUU NPs were synthesized via miniemulsion polymerization according to the procedure described in sequence. The aqueous phase was prepared with $2.00 \mathrm{~g}(20 \mathrm{wt} \%)$ of surfactant relative to the organic phase (unless mentioned otherwise). The organic phase was prepared with $3.30 \mathrm{~g}$ of açaí oil (50 wt \% in relation to the organic phase), $0.60 \mathrm{~g}$ of PEG (10 wt $\%$ in relation to monomers), IPDI and castor oil with molar ratio 1.5:1. The aqueous phase was added slowly to the organic phase under magnetic stirring kept for $5 \mathrm{~min}$ at $40{ }^{\circ} \mathrm{C}$. 
The miniemulsion was then prepared by sonication of the previous emulsion for $120 \mathrm{~s}$ at $70 \%$ amplitude (FisherScientific - Ultrasonic Dismembrator 500, 400 W). Polymerizations were conducted at constant temperature $\left(70{ }^{\circ} \mathrm{C}\right.$, unless mentioned otherwise) and low pressure (1 atm) during 4 hours.

\section{Characterization}

The molar mass of the PUU NPs was determined by gel permeation chromatography (GPC). GPC analyses were carried out by injecting $20 \mu \mathrm{L}$ of a $0.5 \mathrm{wt} \%$ polymer solution (solvent tetrahydrofuran, Merck), previously filtered through a Teflon-filter with a mesh size of $450 \mathrm{~nm}$, into a High Performance Liquid Chromatograph (HPLC, model LC-20A, Shimadzu) equipped with a RID-10A detector in THF at $35{ }^{\circ} \mathrm{C}$. A column set was employed consisting of three $300 \times 8 \mathrm{~mm}$ columns in series (GPC-801, GPC-804 and GPC-807). Molar mass distributions and average molar masses were calculated based on polystyrene standards between $580 \mathrm{~g} \cdot \mathrm{mol}^{-1}$ and 3800000 g.mol ${ }^{-1}$.

The completion of the step polymerization was verified by Fourier transform infrared spectroscopy (FTIR) in the attenuated total reflectance (ATR) mode. The absorption band with peak location at $2272 \mathrm{~cm}^{-1}$, due to $\mathrm{N}=\mathrm{C}=\mathrm{O}$ stretching vibration of the isocyanate groups, was used to identify IPDI. The absorption band with peak location between $1680-1650 \mathrm{~cm}^{-1}$ of $\mathrm{N}-\mathrm{H}$ group of urea and the absorption band between $1740-1700 \mathrm{~cm}^{-1}$ due to stretching vibration of $\mathrm{C}=\mathrm{O}$ group of urethane, were used to identify the PUU, after the reactions had taken place.

Average diameters (intensity averages $-\mathrm{Dp}^{z}$ ) of polymer particles were measured using dynamic light scattering equipment (DLS, Zetasizer Nano S, from Malvern). At least two samples were analyzed for each experimental condition. The morphology of the PUU NP was evaluated by scanning electron microscopy with field emission (SEM-FEG - JEOL JSM-6701F) and transmission electron microscopy (TEM 100Kv - JEM1011). For the SEM analysis, the lyophilized sample was placed on a stub and covered with a thin gold layer and for TEM analysis the lyophilized sample was diluted in water and applied on a carbon-coated copper grid.

\section{Results and Discussion}

\section{Effect of reaction temperature}

In order to study the effect of reaction temperature, four reactions were performed at different temperatures in the range between 50 to $80{ }^{\circ} \mathrm{C}$. Increasing reaction temperature from 50 to $60{ }^{\circ} \mathrm{C}$ and from 60 to $70{ }^{\circ} \mathrm{C}$ led to small increases of the weight average molar mass (Mw), as shown in Table 1 . Increasing further reaction temperature to $80{ }^{\circ} \mathrm{C}$, on the other hand, resulted in a decrease of $\mathrm{Mw}$ from around $17000 \mathrm{~g} / \mathrm{mol}$ for reaction A3 at $70{ }^{\circ} \mathrm{C}$ to around $10000 \mathrm{~g} / \mathrm{mol}$ in reaction $\mathrm{A} 4$ at $80{ }^{\circ} \mathrm{C}$. This decrease is attributed to side reactions of the isocyanate group with water to form urea linkages with the release of carbon dioxide, resulting in lower molar masses. This occurs because the concentration of water in the organic phase increases with temperature.

To confirm if the higher $\mathrm{Mw}$ of reaction $\mathrm{A} 3$ (17297 g/mol) at $70{ }^{\circ} \mathrm{C}$ compared to reaction A4 at $80{ }^{\circ} \mathrm{C}$ was due to a lower formation of urea linkages, PUU samples of these two reactions were analyzed by FTIR, as shown in Figure 1. FTIR results confirmed that when the reaction temperature was increased from $70{ }^{\circ} \mathrm{C}$ to $80{ }^{\circ} \mathrm{C}$ the ratio between the absorption band with peak location between $1680-1650 \mathrm{~cm}^{-1}$ characteristic of the N-H group of urea and the absorption band of urethane $\left(1740-1700 \mathrm{~cm}^{-1}\right)$ was more intense indicating higher formation of urea at higher reaction temperature. Consequently, to avoid the decrease of the molar mass of the PUU $70{ }^{\circ} \mathrm{C}$ was chosen as the reaction temperature for the subsequent reactions to favor the isocyanate-polyol reaction and the urethane formation.

NPs of reaction A3, that resulted in the highest molar mass $(17297 \mathrm{~g} / \mathrm{mol})$, were observed by scanning electron microscopy FEG-SEM, Figure 2. The FEG-SEM analysis allowed verifying the spherical morphology of the PUU NPs with açaí oil. Most particles have a diameter around $100 \mathrm{~nm}$ and the presence of a few bigger particles led to the increase of the intensity average diameter $\left(\mathrm{Dp}^{z}\right)$ measured by DLS (225 nm with PdI $=0.221)$. In Table 1 it can be observed that when reaction temperature was increased from $50{ }^{\circ} \mathrm{C}$ to $80{ }^{\circ} \mathrm{C}$ the variation of the diameters of the particles did not show a clear tendency.

Table 1. Effect of reaction temperature on properties of PUU particles with açaí oil synthesized by miniemulsion polymerization. Reaction conditions: molar ratio IPDI/castor oil $=1.5,10 \mathrm{wt} \%$ of PEG (vs monomers), $20 \mathrm{wt} \%$ of Tween 80 and $50 \mathrm{wt} \%$ of açaí oil (vs organic phase) as costabilizer.

\begin{tabular}{ccccc}
\hline Reaction & $\begin{array}{c}\text { Temperature } \\
\left({ }^{\mathbf{C}}\right)\end{array}$ & $\begin{array}{c}\mathbf{D p} \\
(\mathbf{n m})\end{array}$ & $\begin{array}{c}\text { Mw } \\
(\mathbf{g} / \mathbf{m o l})\end{array}$ & $\begin{array}{c}\mathbf{M n} \\
(\mathbf{g} / \mathbf{m o l})\end{array}$ \\
\hline $\mathrm{A} 1$ & 50 & $269 \pm 1.41$ & 14458 & 7506 \\
$\mathrm{~A} 2$ & 60 & $305 \pm 0.70$ & 15699 & 7961 \\
$\mathrm{~A} 3$ & 70 & $225 \pm 2.82$ & 17297 & 7574 \\
$\mathrm{~A} 3 *$ & 70 & $218 \pm 2.04$ & 18053 & 7756 \\
$\mathrm{~A} 3 * *$ & 70 & $230 \pm 2.41$ & 18010 & 9033 \\
$\mathrm{~A} 4$ & 80 & $304 \pm 0.80$ & 10320 & 6469 \\
\hline
\end{tabular}

* Duplicate and ** triplicate of reaction A3.

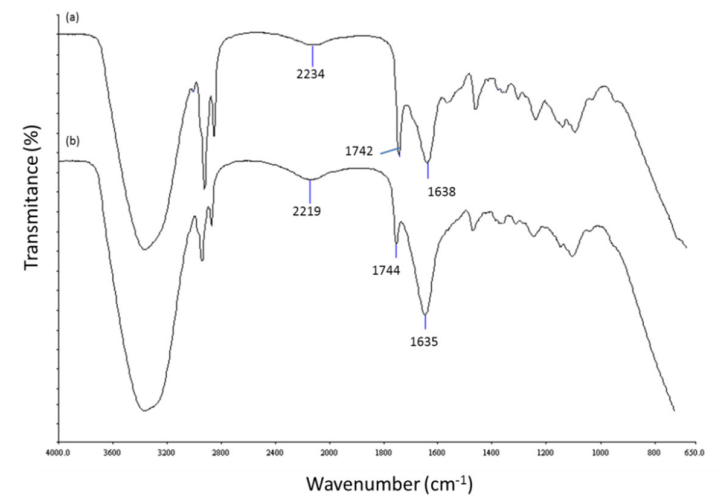

Figure 1. Fourier transform infrared spectra (FTIR) of PUU NPs with açaí oil synthesized by miniemulsion polymerizations $\mathrm{A} 3-70{ }^{\circ} \mathrm{C}$ (a) and $\mathrm{A} 4-80^{\circ} \mathrm{C}$ (b). 


\section{Influence of polyol type}

Table 2 shows the results of miniemulsion polymerizations using different polyol types. Comparing reactions P2 and A18, in which PEG 400 and PEG 1000 were used respectively as polyol it may be observed that the higher molar mass of PEG 1000 resulted in an increase of the molar mass of PUU from $5056 \mathrm{~g} / \mathrm{mol}$ to $7213 \mathrm{~g} / \mathrm{mol}$. On the other hand, when glycerol was used as monomer it was possible obtain PUU NPs with an even lower molar mass $(4324 \mathrm{~g} / \mathrm{mol})$. These results indicate that the increase of the molar mass of the polyol leads to an enhancement of the molar mass of the polymer and this effect can be attributed to the increase of the size of the repeated units in the PUU chains. In addition, the introduction of PEG as co-monomer of castor oil resulted in an enhancement of the molar mass. This effect was more pronounced when PEG 1000 was used.

The polyol type also affected particle size and the polydispersity index (PdI). While reaction P2 with PEG 400 resulted in particles with Dp equal to $124 \mathrm{~nm}$ (with $\mathrm{PdI}=0.172$ ), reaction A18 with PEG 1000 as polyol led to the formation of particles with Dp equal to $191 \mathrm{~nm}$ with $\mathrm{PdI}=0.507$. This increase of Dp and PdI with the molar mass of PEG is attributed to the increase of the viscosity of the dispersed phase turning the miniemulsification more difficult. Since miniemulsification conditions were not varied among the reactions for allowing a better comparison, miniemulsification was more effective for

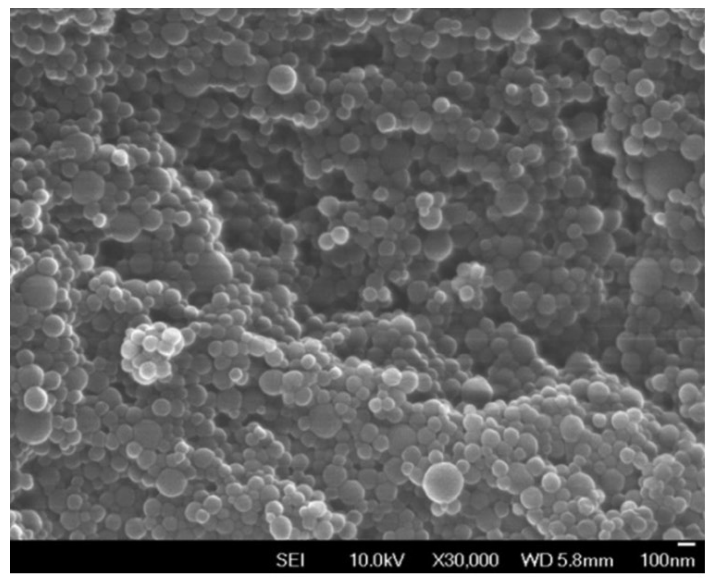

(a) lower viscosities of the dispersed phase. In the same way, when PEG was used as co-monomer of castor oil a small increase was observed in the particle size, especially when PEG 1000 was used. Zanetti-Ramos et al. observed an increase in the particle diameter from $246 \mathrm{~nm}$ to $261 \mathrm{~nm}$ when PEG 400 was used as co-monomer in the synthesis of PUU from castor oil and IPDI ${ }^{[9]}$.

While polyols with low molar mass as PEG 400 and, especially, glycerol resulted in smaller particles with narrow size distributions, as shown in Figure 3, polyols with higher molar mass as PEG 1000 and castor oil led to the formation of broad particle size distributions, as also observed in SEM and TEM images of reaction A3 with PEG 1000 and castor oil as polyol in Figure 2.

\section{Effect of surfactant type}

Colloidal stability is usually determined by the type and amount of the employed surfactants ${ }^{[5]}$. In this work, different nonionic surfactants were evaluated resulting in miniemulsion and polymeric dispersions with different particle sizes and stabilities. According to the results shown in Table 3, surfactants with an hydrophiliclipophilic balance (HLB) value of 15 and 16 as Tween 80 or the pair Luthensol AT25/Span 80 resulted in the smallest particles (respectively $225 \mathrm{~nm}$ and $238 \mathrm{~nm}$ ) with the narrowest distribution (PdI) 0.221 and 0.241, respectively.

In addition, the average particle sizes and polydispersity index of the PUU particles with açaí oil

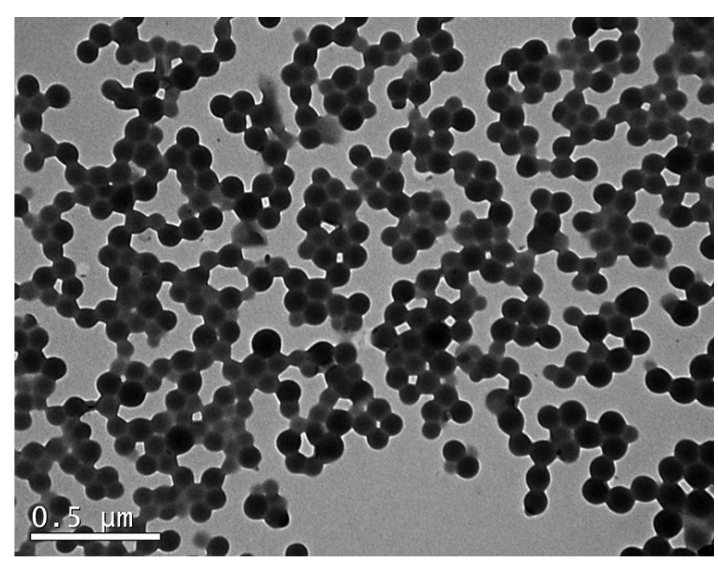

(b)

Figure 2. (a) SEM and (b) TEM images of PUU NPs with açaí oil prepared by miniemulsion polymerization with molar ratio IPDI/ castor oil = 1.5, $10 \mathrm{wt} \%$ of PEG 1000 (vs monomers), $20 \mathrm{wt} \%$ of Tween 80 and 50 wt \% of açaí oil (vs organic phase).

Table 2. Effect of polyol type on properties of PUU particles with açaí oil synthesized by miniemulsion polymerization. Reaction conditions: $20 \mathrm{wt} \%$ of Tween 80 and $50 \mathrm{wt} \%$ açaí oil (vs organic phase).

\begin{tabular}{clccccc}
\hline Reaction & \multicolumn{1}{c}{ Polyol } & $\begin{array}{c}\text { Polyol Mw } \\
(\mathbf{g} / \mathbf{m o l})\end{array}$ & $\begin{array}{c}\text { Dp } \\
(\mathbf{n m})\end{array}$ & PdI & $\begin{array}{c}\text { Mw } \\
(\mathbf{g} / \mathbf{m o l})\end{array}$ & $\begin{array}{c}\text { Mn } \\
(\mathbf{g} / \mathbf{m o l})\end{array}$ \\
\hline P5 & Castor oil & 928 & $179 \pm 3.53$ & 0.253 & 8999 & 5753 \\
A3 & PEG 1000/Castor oil & $1000 / 928$ & $225 \pm 2.82$ & 0.221 & 17297 & 7574 \\
P1 & PEG 400/Castor oil & $400 / 928$ & $197 \pm 2.61$ & 0.240 & 11178 & 6861 \\
A18 & PEG 1000 & 1000 & $191 \pm 4.94$ & 0.507 & 7213 & 5465 \\
P2 & PEG 400 & 400 & $124 \pm 4.17$ & 0.172 & 5056 & 3848 \\
G1 & Glycerol & 92 & $135 \pm 1.93$ & 0.071 & 4324 & 3362 \\
\hline
\end{tabular}




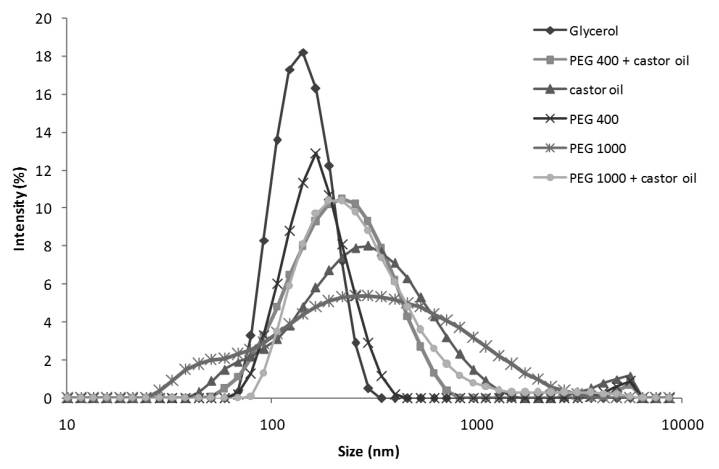

Figure 3. Intensity particle size distributions (measured by DLS) of PUU NPs with açaí oil synthesized by step miniemulsion polymerizations with different polyol types.

Table 3. Effect of surfactant type on properties of PUU particles with açaí oil synthesized by miniemulsion polymerization. Reaction conditions: molar ratio IPDI/castor oil $=1.5,10 \mathrm{wt} \%$ of PEG (vs monomers) and 50 wt \% açaí oil (vs monomers) as costabilizer, $20 \mathrm{wt} \%$ surfactant.

\begin{tabular}{clccc}
\hline Reaction & \multicolumn{1}{c}{ Surfactant } & HLB & $\begin{array}{c}\text { Dp } \\
(\mathbf{n m})\end{array}$ & PdI \\
\hline S1 & Tween 80 & 15 & $225 \pm 2.82$ & 0.221 \\
S2 & Span 80 & 4.3 & - & - \\
S3 & Tween 80/Span 80* & 12 & $338 \pm 8.13$ & 0.297 \\
S4 & Lutensol AT 25 & 20 & $469 \pm 7.70$ & 0.517 \\
S5 & Lutensol AT25/Span 80** & 16 & $238 \pm 4.24$ & 0.241 \\
\hline
\end{tabular}

*Tween 80/Span 80 mass ratio: 72/28 and **Lutensol AT 25/Span 80 mass ratio: $74.5 / 25.5$.

synthesized with these surfactants did hardly show any variations one year after the polymerizations. On the other hand, when only Lutensol AT 25 with HLB $=20$ was used as surfactant the average particle diameter was considerably higher, $469 \mathrm{~nm}$ with a broader distribution $(\mathrm{PdI}=0.517)$. Surfactants with HLB values between 8 and 18 are used for oil-water systems $(\mathrm{O} / \mathrm{W})$ and surfactant with smaller HLB values are indicated for water-oil systems (W/O $)^{[20]}$. As expected, when only Span 80 with HLB $=4.3$ were used as surfactant miniemulsion was less stable with the formation of a precipitate after 4 hours.

\section{Effect of surfactant concentration}

Surfactant concentration is another important factor in a miniemulsion polymerization since higher surfactant concentrations allow the stabilization of larger interfacial areas and thus favor the formation of smaller droplets/particles. Nevertheless, the concentration of the surfactant in the continuous phase of a miniemulsion should be below its critical micellar concentration to avoid the presence of micelles. In the previous section it was shown that nonionic surfactants as Tween 80 could be efficiently used in the synthesis of PUU NPs with açaí oil. Increasing the amount of surfactant Tween 80 from $5 \mathrm{wt} \%$ to $20 \mathrm{wt} \%$ (see Table 4 ) allows to reduce the PUU particle size and increase the molar mass.

Increasing Tween 80 concentration from 5wt \% to $20 \mathrm{wt} \%$ resulted in a decrease in the particle size (Table 4), from $406 \mathrm{~nm}$ to $225 \mathrm{~nm}$ and the same behavior
Table 4. Effect of surfactant (Tween 80) concentration on the properties of PUU particles with açaí oil synthesized by miniemulsion polymerization. Reaction conditions: molar ratio IPDI/casrtor oil $=1.5,10 \mathrm{wt} \%$ of PEG (vs monomers) and $50 \mathrm{wt} \%$ açaí oil (vs monomers) as costabilizer.

\begin{tabular}{cccccc}
\hline Reaction & $\begin{array}{c}\text { Tween 80 } \\
\text { (wt \%) }\end{array}$ & $\begin{array}{c}\text { Dp } \\
(\mathbf{n m})\end{array}$ & PdI & $\begin{array}{c}\text { Mw } \\
(\mathbf{g} / \mathbf{m o l})\end{array}$ & $\begin{array}{c}\text { Mn } \\
(\mathbf{g} / \mathbf{m o l})\end{array}$ \\
\hline $\mathbf{A 5}$ & $5 \%$ & $406 \pm 6.36$ & 0.309 & 10630 & 6504 \\
A6 & $10 \%$ & $331 \pm 5.65$ & 0.266 & 12654 & 6991 \\
A3 & $20 \%$ & $225 \pm 2.82$ & 0.221 & 17297 & 7574 \\
\hline
\end{tabular}

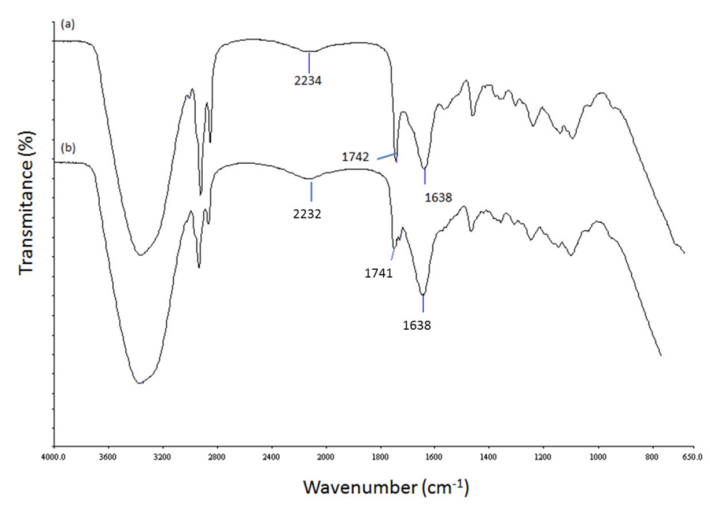

Figure 4. Fourier transform infrared spectra (FTIR) of PUU NPs with açaí oil synthesized by miniemulsion polymerizations A3 - 20 wt $\%$ Tween 80 (a) and A5 - 5 wt \% Tween 80 (b).

can be observed for the polydispersity index, which decreased from 0.309 to 0.221 , for, respectively, 5 wt $\%$ and $20 \mathrm{wt} \%$ surfactant concentration. The increase of Tween 80 concentration helps in the stabilization of the monomer drops during sonication decreasing their coalescence and, thus, leading to the formation of smaller particles with a more narrow distribution.

The increase of the molar mass of PUU from $10523 \mathrm{~g} / \mathrm{mol}$ for $5 \mathrm{wt} \%$ of Tween 80 to $17297 \mathrm{~g} / \mathrm{mol}$ for $20 \mathrm{wt} \%$ of Tween 80 can be related to a higher coverage of PUU particles when 20 wt \% of Tween 80 was used, decreasing the reaction between isocyanate groups and water and, consequently, decreasing the formation of urea groups that are associated with the formation of lower molar mass polymer. In Figure 4 it can be observed that the absorption band with peak location between $1680-1650 \mathrm{~cm}^{-1}$, characteristic of the $\mathrm{N}-\mathrm{H}$ bond, was more intense in reaction A5 with a lower surfactant concentration (5 wt \%) indicating higher formation of urea than the absorption band of urethane between $1740-1700 \mathrm{~cm}^{-1}$.

\section{Conclusion}

In this paper, we have shown that the choice of reaction temperature and polyol type is very important in the synthesis of PUU NPs with açaí oil since both strongly affect the molar mass of the formed polymer. The size of the PUU NPs and the molar mass were also influenced by the surfactant type and concentration. Nonionic surfactant Tween 80 allowed the production of PUU NPs with $225 \mathrm{~nm}$ and a molar mass around $17000 \mathrm{~g} / \mathrm{mol}$. Particle 
morphology was verified by scanning electron with field emission and transmission electron microscopies and FTIR spectroscopy allowed to confirm the completion of the polymerization and verifying the products obtained at the end of the reactions.

\section{Acknowledgements}

The authors thank the financial support from CAPES (Coordenação de Aperfeiçoamento de Pessoal de Nível Superior) and $\mathrm{CNPq}$ (Conselho Nacional de Desenvolvimento Científico e Tecnológico), TEM analyses from Laboratório Central de Microscopia Eletrônica (LCME) of Universidade Federal de Santa Catarina and Beraca for providing açaí oil.

\section{References}

1. Ding, B. M.; He, X.; Wang, Z.; LI, J.; Tan, H.; Fu, Q. \& Gu, Q. - Biomaterials, 32, p.9515 (2011). http://dx.doi. org/10.1016/j.biomaterials.2011.08.074

2. Souto, E. B.; Severino, P.; Santana, M. H. A. - Polímeros, 22, p.96 (2012). http://dx.doi.org/10.1590/ S0104-14282012005000006

3. Zanetti-Ramos, B. G.; Fritzen-Garcia, M. B.; De Oliveira, C. S.; Pasa, A. A.; Soldi, V.; Borsali, R. \& Pasa, T. B. C. - Mat. Sci. and Eng: C, 29, p.638 (2009). http://dx.doi. org/10.1016/j.msec.2008.10.040

4. Gaudin, F. \& Sintes-Zydowicz, N. Col. - Surf. A: Phys Eng. Asp., 331, p.133 (2008). http://dx.doi.org/10.1016/j. colsurfa.2008.07.028

5. Torini, L.; Argillier, J. F. \& Zydowicz, N. - Macromolecules, 38, p.3225, (2005). http://dx.doi. org/10.1021/ma047808e

6. Gaudin, F. \& Sintes-Zydowicz, N. - Col. Surf. A: Phys. Eng. Asp., 384, p.698, (2011). http://dx.doi.org/10.1016/j. colsurfa.2011.05.050
7. Jabbari, E. \& Khakpour, M. - Biomaterials, 21, p.2073 (2000). http://dx.doi.org/10.1016/S0142-9612(00)00135-6

8. Bouchemal, K.; Briançon, S.; Perrier, E.; Fessi, H.; Bonnet, I. \& Zydowicz, N. - Inter. J. Phar., 269, p.89, (2004). http:// dx.doi.org/10.1016/j.ijpharm.2003.09.025

9. Zanetti-Ramos, B. G.; Lemos-Senna, E.; Soldi, V.; Borsali, R.; Cloutet, E. \& Cramailh, P. - Polymer, 47, p.8080, (2006). http://dx.doi.org/10.1016/j.polymer.2006.09.057

10. Antonietti, M. \& Landfester, K. - Polym. Sci., 27, p.689 (2002)

11. Asua, J. M. - Progr. Polym. Sci., 27, p. 1283 (2002). http:// dx.doi.org/10.1016/S0079-6700(02)00010-2

12. El-Aasser, M. S. \& Sudol, E. D. - J. C. T. Res., 1, p. 21 (2004).

13. Tiarks, F. \& Landfester, K. - J. Pol. Sci. A: Pol. Chem., 39, p.2520, (2001). http://dx.doi.org/10.1002/pola.1228

14. Barrére, M. \& Landfester, K. - Macromolecules, 36, p.5119, (2003). http://dx.doi.org/10.1021/ma025981+

15. Zhang, Q.; Shi, Y.; Zhan, X. \& Chen, F. - Col. Surf. A: Phys. Eng. Asp. 393, p.17, (2012). http://dx.doi.org/10.1016/j. colsurfa.2011.10.016

16. Coutinho, F. M. B.; Delpech, M. C.; Alves, T. L. \& Gomes, A. S. - Polímeros, 12, p.248, (2002). http://dx.doi. org/10.1590/S0104-14282002000400007

17. Nascimento, R. J. S.; Couri, S.; Antoniassi, R. \& Freitas, S. P. - Ver. Bras. Frutic., 30, p.498, (2008). http://dx.doi. org/10.1590/S0100-29452008000200040

18. Machado, A. C. H. R. - "Desenvolvimento e avaliação da incorporação e liberação de óleo de açaí em hidrogéis de poli(N-vinil-2-pirrolidona)", Dissertação de Mestrado, Instituto de Pesquisas Energéticas e Nucleares (2010).

19. Narine, S. S. \& Kong, X. - "Bailey's Industrial Oil and Fat Products", Wiley, (2005).

20. Rosen, M. J. - "Surfactants and Interfacial Phenomena", Wiley-Interscience, New York (2004). http://dx.doi. org/10.1002/0471670561 